\title{
De los libros impresos a la Nueva corónica. Los grabados como fuentes de Guaman Poma
}

\author{
Audrey Prévotel \\ Universidad de Poitiers, CRLA-Archivos \\ audrey.prevotel@gmail.com \\ \&
}

Resumen

Uno de los aspectos más originales de la Nueva Corónica es su componente iconográfico, que representa un tercio del manuscrito. La cuestión de los modelos que utilizó Guaman Poma para realizar esos dibujos ha sido bastante discutida, pero pocas veces se mencionaron y analizaron, en este marco, los grabados europeos. El presente artículo pretende poner en evidencia la fuerte influencia de las estampas en la iconografía guamanpomiana e identificar algunas fuentes posibles. Nos interrogaremos también sobre los motivos y las consecuencias de la utilización de tales modelos así como sobre el destinatario de la Nueva Corónica.

Palabras claves: Perú colonial, Guaman Poma, iconografía, grabados.

\begin{abstract}
One of the most original aspects of the Nueva Corónica is the iconographical component that represents one third of the manuscript. The question of the models used by Guaman Poma to realize his drawings has been quite debated, but the European engravings have never really been properly mentioned or analyzed. This article intends to highlight the important influence of these engravings on Guaman Poma's iconography and identify some possible sources. We will also question the reasons and consequences of the use of such models, and the reader of the Nueva Corónica.
\end{abstract}

Keywords: Colonial Peru, Guaman Poma, iconography, engravings.

Recibido: 5/11/14 Aceptado: 29/11/14 Publicado on line: 10/1/15 
Audrey Prévotel

\section{Introducción}

A pesar de que Guaman Poma terminó su Primer Nueva Corónica y Buen Gobierno hace 400 años, se la puede leer desde hace sólo unos 80 años. Fue en 1936 cuando el Institut d'ethnologie de París publicó el facsímile de esta obra actualmente muy estudiada por los filólogos, lingüistas, antropólogos, historiadores e historiadores del arte. De hecho, este manuscrito de 1200 páginas contiene 399 dibujos que hicieron -y siguen haciendo- correr mucha tinta. Dado que Guaman Poma era un indio ladino, no cabe duda de que, en sus imágenes, coexisten y se mezclan elementos de las culturas europea y andina. Algunos estudiosos como Emilio Mendizábal Losack (1961), Rolena Adorno (1979) y Mercedes López-Baralt (1988) se interesaron en los conceptos prehispánicos discernibles en los dibujos mientras que Teresa Gisbert (1980, 1992), Maarten van de Guchte (1992), Marie-Claude Cabos Fontana (2000) y Augusta Holland (2008) trabajaron más bien sobre los modelos europeos del cronista andino. Sus posibles influencias o fuentes visuales ${ }^{1}$ son muy numerosas: Guaman Poma puede haberse inspirado en su propia experiencia (acontecimientos que presenció), en la pintura (lienzos y frescos), la vidriera, los pliegos sueltos y los grabados que ilustraban los libros impresos. Ahora bien, las estampas fueron poco estudiadas en relación con los dibujos de Guaman Poma a pesar de su gran influencia en el arte virreinal. Cabe recordar que los artistas indígenas solían utilizarlas como modelos para sus propias realizaciones (Ojeda 2009: 15).

El estatus de ladino de Guaman Poma explica que, primero para su formación y después gracias a ella, haya tenido acceso a libros impresos y, entre ellos, a libros ilustrados. Habría podido consultar la biblioteca del extirpador de idolatrías Cristóbal de Albornoz, al servicio del cual dice haber trabajado como intérprete; o la del mercedario Martín de Murúa, a quien menciona directamente en su crónica, y para quien realizó numerosos dibujos. ${ }^{2}$ La relación entre los dibujos de la Nueva Corónica y los grabados europeos merece pues un examen detallado, a fines de evaluar hasta qué punto las láminas pueden ser consideradas como fuentes de Guaman Poma, tratar de identificar algunos modelos y analizar la manera como el dibujante los adaptó a su propio mensaje. Para dar respuesta a estos interrogantes, en un primer tiempo describiremos las analogías que existen entre catorce dibujos de Guaman Poma y catorce grabados europeos, sobre seis temas distintos. Gracias a dichas comparaciones

1 La historiadora del arte Cécile Michaud recuerda que existe un debate sobre el uso del término "influencia", a causa de su relativa imprecisión. Añade que se le pueden preferir los conceptos de modelos o fuentes visuales (Michaud 2009: 11).

2 Los trabajos más recientes sobre las relaciones entre Guaman Poma y Murúa son los de Rolena Adorno e Ivan Boserup (2008) por un lado, y Juan Ossio y Tom Cummins por otro (2013). 
previas, podremos, en un segundo tiempo, interesarnos en el impacto de las láminas en la iconografía guamanpomiana. El corpus, de índole iconográfica, se compone de trece dibujos de la Nueva Corónica, uno del manuscrito de Murúa comúnmente llamado Galvin Murúa, ${ }^{3}$ nueve grabados reproducidos por los investigadores Clive Griffin (1988) y James Lyell (2006), y cinco imágenes sacadas de una edición de 1624-1625 de un famoso catálogo de alegorías que influyó mucho en las artes plásticas (Peña 2011: 95): Della novissima iconologia di Cesare Ripa Perugino.

\section{Examen comparativo}

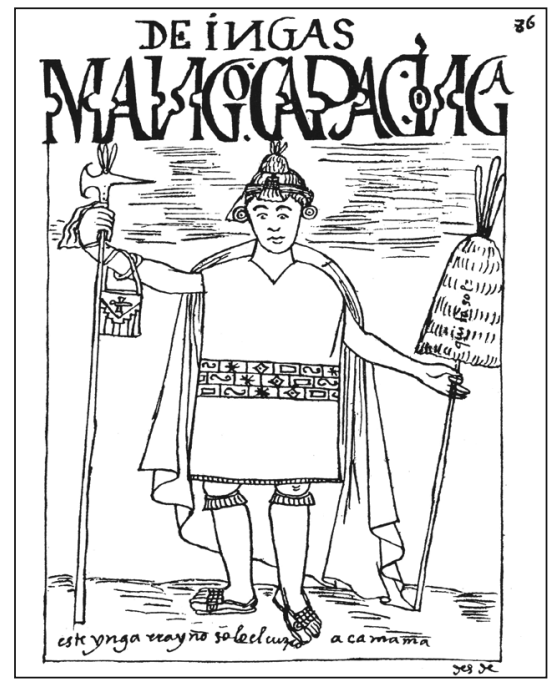

Figura 1

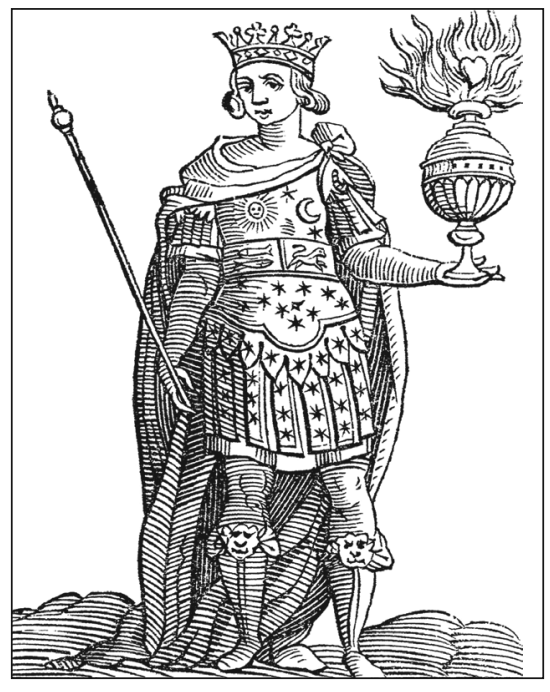

Figura 1

3 Se lo denomina manuscrito Galvin porque forma parte de la colección privada de Sean Galvin (Dublin). 


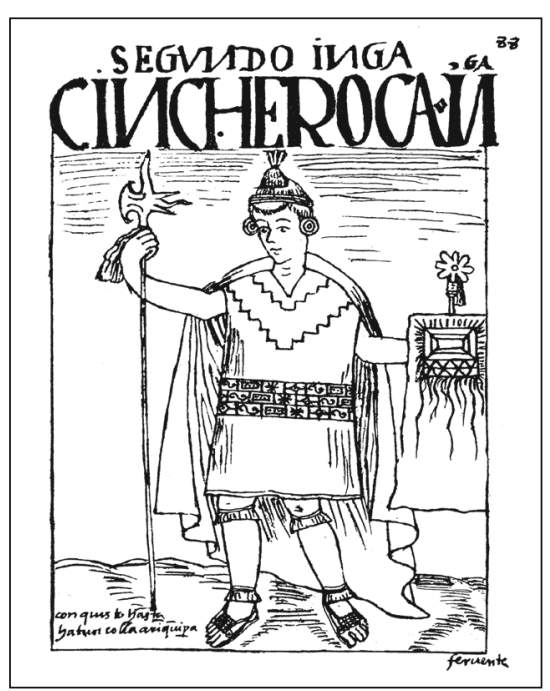

Figura 3

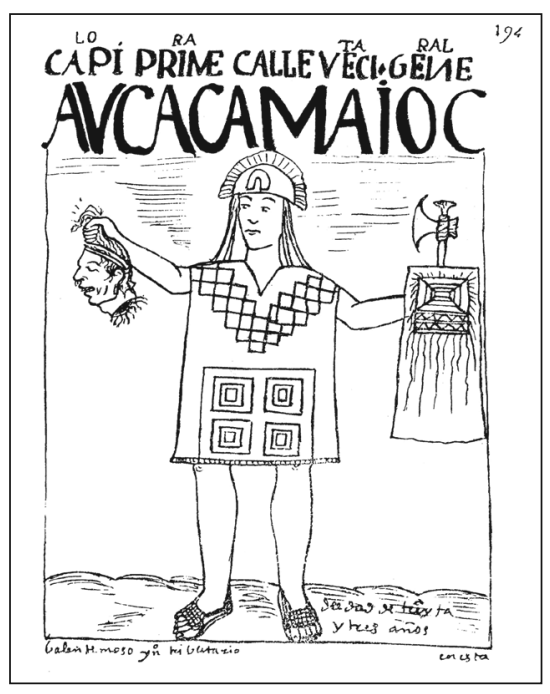

Figura 5

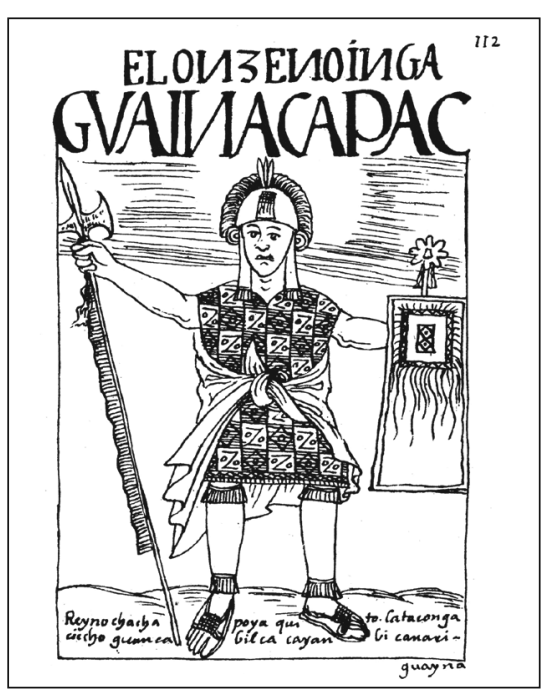

Figura 4

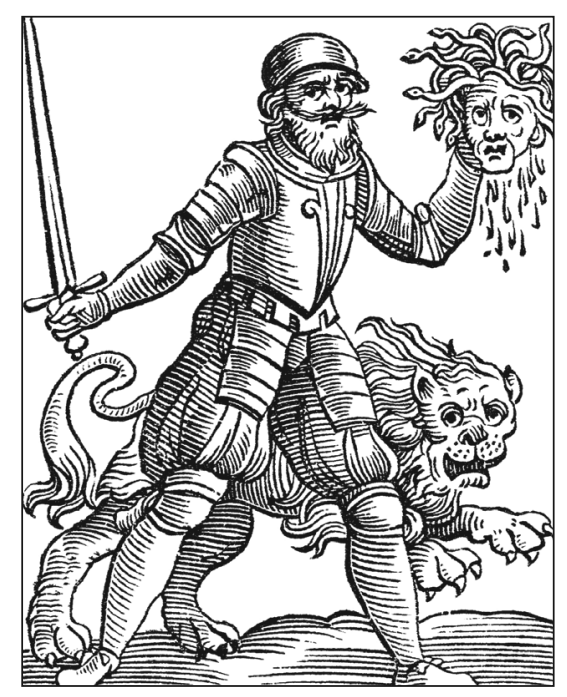

Figura 6 
El primer caso que nos interesa incluye varios retratos masculinos de la Nueva Corónica: el Inca Manco Capac (Guaman Poma 1989: 86) (Fig. 1), el Inca Sinchi Roca (ibid.: 88) (Fig. 3), el Inca Huayna Capac (ibid.: 112) (Fig. 4) y el indio de la primera calle ${ }^{4}$ (ibid.: 194) (Fig. 5). Podemos relacionar estos cuatro dibujos con dos grabados de la Iconologia de Ripa: la alegoría del Cielo (Ripa 1624-5: 102) (Fig. 2) y la del Temor (ibid.: 629) (Fig. 6). Numerosos detalles de la primera representación alegórica se encuentran también en los retratos de los soberanos incas: la postura de los pies, la presencia de adornos en las pantorrillas, la lanza en la mano derecha, el brazo izquierdo en posición horizontal y que tiene otro objeto, la capa, el cinturón y la corona. Hasta notamos que la forma levemente rizada del cabello del soberano de la Iconologia tiene algo que ver con los ornamentos auriculares de los Incas. Además, el Cielo y Sinchi Roca (Fig. 3) tienen en común la orientación de la cabeza, levemente girada a su derecha, para ofrecer un retrato de tres cuartos. Asimismo, la alegoría del Miedo (Fig. 6), encarnada por un soldado, tiene una cabeza cortada en una mano y un arma afilada en la otra, como el indio de la primera calle en la Nueva Corónica (Fig. 5). Por fin, en las seis imágenes se nota la ausencia de decorado, la forma ondulada del suelo y el uso del rayado horizontal para representarlo.

Después de los retratos de varones, interesémonos en uno de los retratos femeninos más famosos de la Nueva Corónica, el de la Coya Mama Huaco (Guaman Poma 1989: 120) (Fig. 7), madre y esposa del Inca Manco Capac. Sentada en una alfombra, frente al lector, la reina tiene en la mano izquierda un espejo que refleja su cara. El motivo del espejo/reflejo se encuentra también en la obra de Ripa para las alegorías de la Felicidad (Ripa 1624-5: 129) (Fig. 9), de la Prudencia (ibid.: 536) (Fig. 10) y de la Angustia (ibid.: 42) (Fig. 11), y en una estampa reproducida por Lyell (Lyell 2006: 118) (Fig. 8), en la que una mujer, parada en un bote, se está peinando con la mano derecha y tiene un espejo que refleja su cara en la mano izquierda. Notemos que, tanto en este grabado como en el dibujo de Guaman Poma, los dos objetos asociados con la mujer son el espejo y el peine.

4 En la Nueva Corónica, Guaman Poma distingue diez "calles" de varones y diez de mujeres, que no son vías o caminos como se lo podría creer sino categorías de edad. En el tercer volumen de la edición de la Nueva Corónica realizada por Franklin Pease, más precisamente en el vocabulario compuesto por Jan Szemi $\square$ ski, para la entrada "calle, calli", leemos: "kalli = lote, grupo como resultado de división” (Guaman Poma 2008, t. 3: 33). 


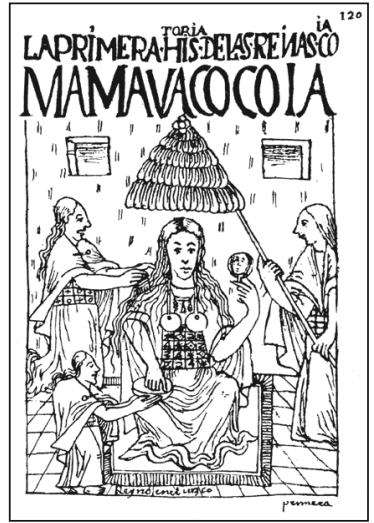

Figura 7

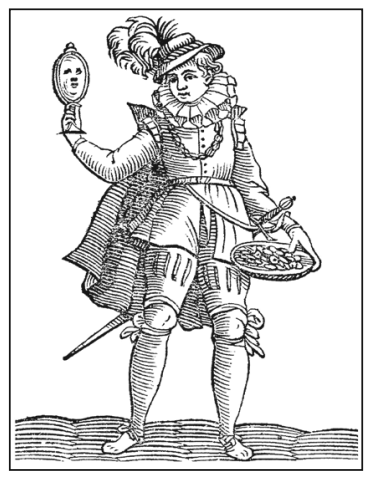

Figura 9

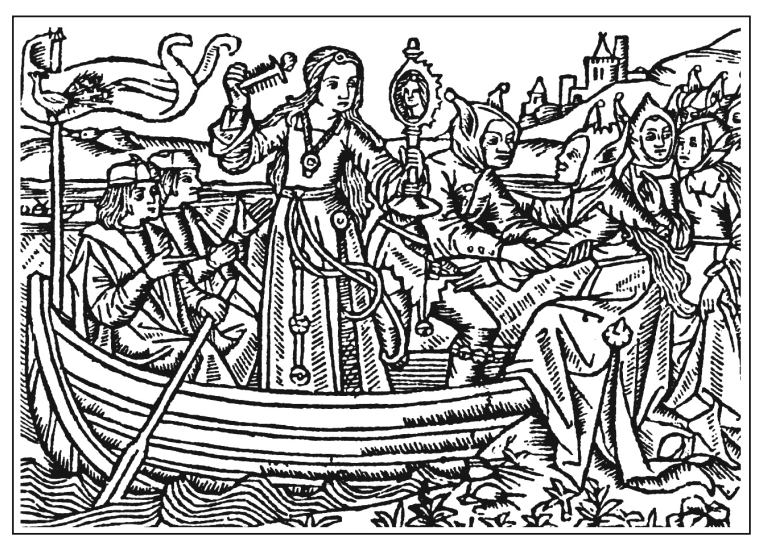

Figura 8

El siguiente dibujo que vamos a comentar se ubica en el capítulo sobre los ídolos (Guaman Poma 1989: 261) (Fig. 12). El Inca, quien lleva el llawt'u (cinta real), la maskapaycha (borla) y el champi (arma), está parado a la derecha, desde el punto de vista del lector. A sus pies, se ven doce divinidades prehispánicas o huacas, pequeñas figuras y piedras que forman un círculo. El soberano se dirige a ellas, con el índice derecho levemente curvado hacia arriba, lo que corresponde con un gesto de poder. 


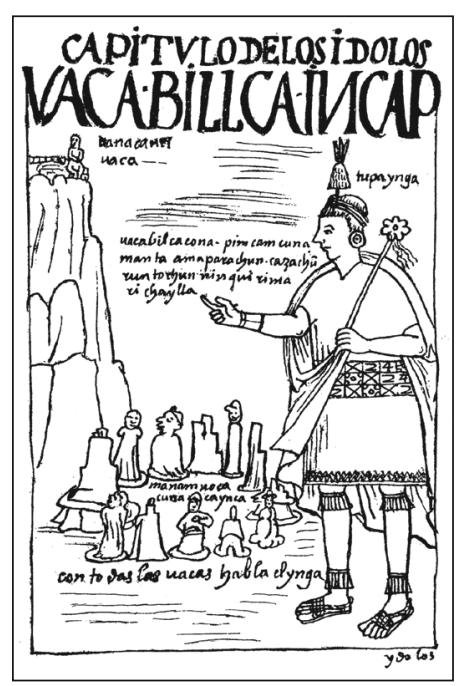

Figura 12

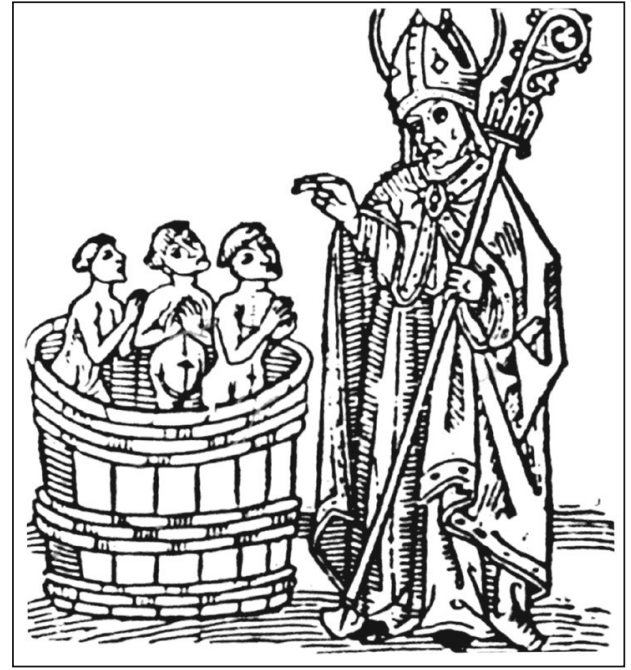

Figura 13

Este dibujo puede ser cotejado con un grabado del taller de los Cromberger (Griffin 1988: 1618 - lámina 1075) (Fig. 13) en el que un obispo, quien lleva la mitra y tiene el báculo episcopal en la mano izquierda, señala a tres pequeños individuos desnudos en una cubeta con la derecha. Tales elementos permiten identificar a san Nicolás; según la leyenda popular, dicho santo resucitó a tres niños que habían sido capturados y matados por un hostelero, quien luego había puesto los restos humanos en un saladero. ${ }^{5} \mathrm{Al}$ comparar las dos imágenes, comprobamos que su esquema de composición es muy parecido: un personaje está de pie a la derecha del lector, con un atributo de poder en la cabeza y otro en forma de bastón en la mano izquierda, y señala con la mano derecha; se parecen también la posición de los dedos de esa mano y la

5 El historiador del arte Louis Réau indica que ésta no fue la historia original. En la Leyenda Dorada (siglo XIII), se puede leer que tres príncipes fueron injustamente encarcelados y condenados a muerte. Al enterarse de su próxima ejecución, se pusieron a lanzar gemidos, rasgaron su ropa y rogaron a san Nicolás que los salvara, lo que hizo (Vorágine 2004: 32). Ahora bien, en las obras hagiográficas del siglo XVI, herederas de la Leyenda, después de este milagro, se relata que un posadero mató a dos ricos jóvenes estudiantes para poder robarlos. Descuartizó los cuerpos y los puso en una tina de sal, pero san Nicolás los resucitó (Vega 1580: fo. 6r). Réau explica que el segundo milagro nació de una deformación del primero, debida a la falsa interpretación de una imagen. En la Edad Media, se solía representar a los prisioneros en una torre cortada en el medio; por eso los tres oficiales encarcelados se convirtieron en tres niños (porque eran mucho más pequeños que el santo), y la torre en saladero (Réau 1956: 977). 
orientación del bastón; a la izquierda, varios personajitos forman un círculo o están ubicados en un objeto circular. Incluso llama la atención el hecho de que el obispo parece tener su capa en la mano izquierda, además del báculo; de una manera similar, el Inca agarra su capa con la mano izquierda, aunque se trata de una parte de tela del lado opuesto.

En otro capítulo de la Nueva Corónica, el que concierne la justicia de los incas, un dibujo representa la lapidación de una pareja adúltera (Guaman Poma 1989: 306) (Fig. 14). Uno de los grabados reproducidos por Lyell representa también una escena de lapidación, pero se trata de la de Ramón Llull (Lyell 2006: 65) (Fig. 15), filósofo y erudito del siglo XIII nacido en Mallorca, famoso por sus escritos y su acción misionera en África (ibid.: 64). Fue durante una de esas estancias que murió lapidado por musulmanes en Argelia.

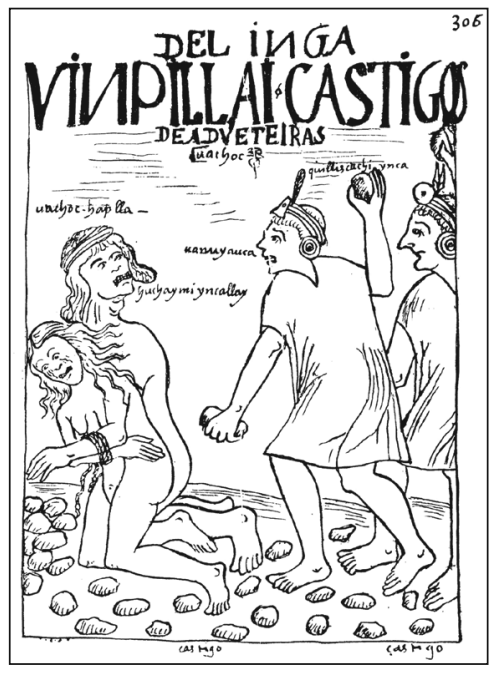

Figura 14

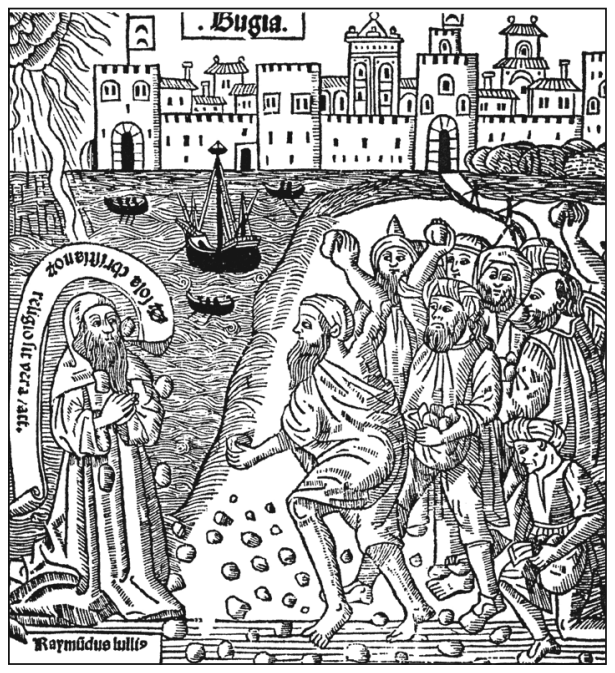

Figura 15

Además de la semejanza temática con el dibujo de la Nueva Corónica -la lapidación-, notamos una similitud en el esquema de composición, con la(s) víctima(s) a la izquierda y los verdugos a la derecha, desde el punto de vista del lector. Los personajes están en posiciones similares, con la(s) víctima(s) de rodillas y los verdugos de pie; el más cercano a la víctima tiene los brazos y las piernas en la misma actitud, el talón derecho levemente despegado del suelo, y los pliegues de la ropa que le marcan las nalgas; en las piedras, el rayado permite dar cierta impresión de volumen. 
Más adelante en el manuscrito, en la parte relativa a la época colonial, dos dibujos representan escenas de comidas (Guaman Poma 1989: 603, 505) (Fig. 16). Tienen algunas concordancias con dos grabados de los Cromberger sobre el mismo tema (Griffin 1988: 1394 - lá. 141, 142) (Fig. 17).

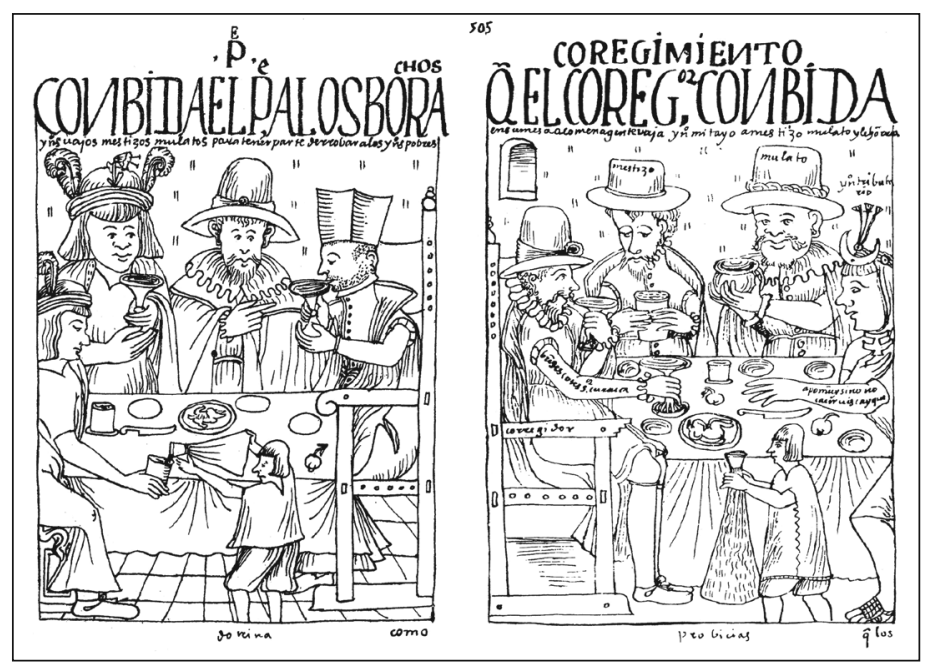

Figura 16

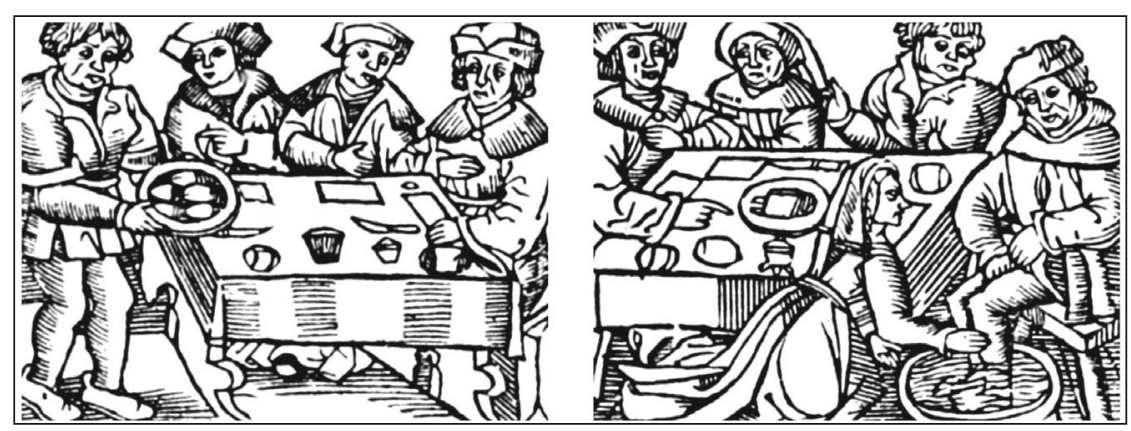

Figura 17

Por supuesto, los personajes son distintos ya que en el caso del dibujante andino, son miembros de la sociedad colonial (españoles, mestizos, mulatos, caciques) mientras que en el caso de las láminas, son modestos europeos, aparentemente reunidos en un albergue. Además de la correspondencia temática y escénica, notamos algunas analogías respecto a la mesa: en las 
cuatro imágenes, la búsqueda de perspectiva da una impresión de inclinación; está cubierta con un mantel; la comida en los platos es muy esquemática. No obstante, vemos también diferencias indiscutibles: los cuchillos son nítidamente distintos puesto que el mango de los de Guaman Poma tiene un corchete; los platos españoles son rectangulares; los manteles europeos son más cortos que los coloniales y los símbolos de los pliegues son curvados en la Nueva Corónica y rectos en los grabados.

Terminamos el ejercicio comparativo con representaciones de parejas: cuatro son sacadas de la Nueva Corónica (Guaman Poma 1989: 856, 534, 542, 394) (Fig. 18) y otras cuatro del taller de los Cromberger (Griffin 1988: 1560 lá. 914; 1397 - lá. 167; 1574 - lá. 957; 1403 - lá. 210) (Fig. 19).
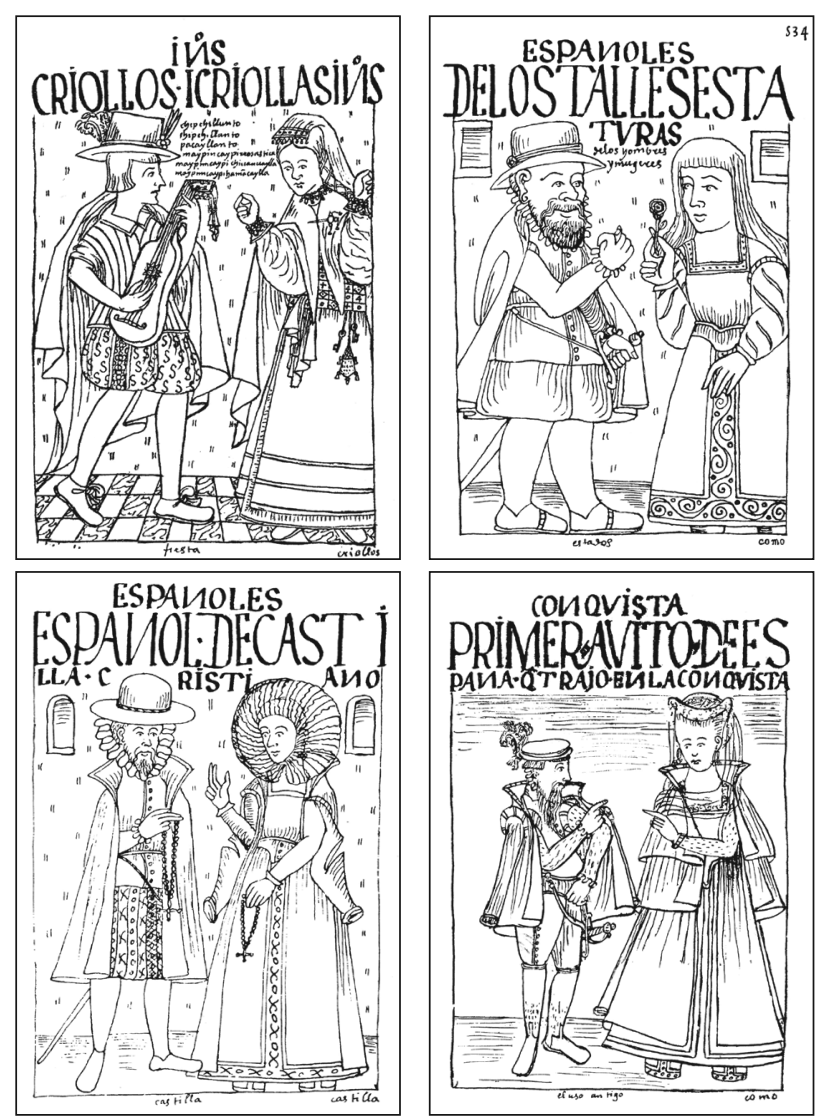

Figura 18 

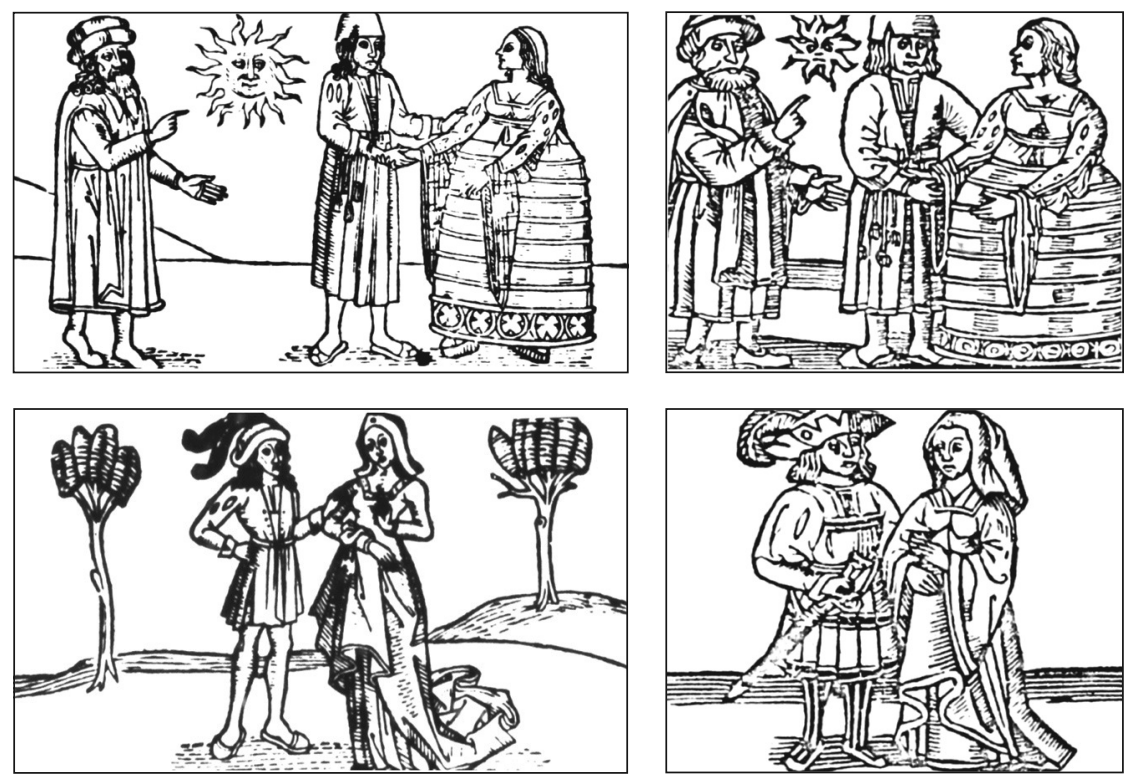

Figura 19

En las ocho imágenes, desde el punto de vista del lector, el varón está a la izquierda y la mujer a la derecha, pero ésta es la única concordancia. La ropa y los sombreros son distintos ya que corresponden a la época, la zona geográfica y el nivel social; tres de las parejas de Guaman Poma están en un decorado interior (baldosas, ventanas, paredes) cuando tres de las parejas europeas están en un lugar exterior (sol, árboles); las manos y los cuerpos de los individuos dibujados por el cronista indígena no se tocan mientras que todas las parejas de las estampas se tienen por la mano o por el brazo; por fin, el rayado de la ropa de los personajes de Guaman Poma es esencialmente vertical mientras que es horizontal o diagonal para la vestimenta de las parejas de los Cromberger.

\section{Fuentes e interpretaciones}

Nos parece ahora innegable que los grabados constituyeron, para Guaman Poma, una fuente de primer orden en la realización de sus dibujos. Las dos estampas reproducidas que llaman más particularmente la atención por sus afinidades con los dibujos de la Nueva Corónica están vinculadas con la religión cristiana ya que se trata del milagro de san Nicolás (Fig. 13) y del martirio de 
Ramón Llull (Fig. 15). En el primer caso, a pesar de la ausencia de relación temática entre el modelo supuesto y el dibujo asociado, las analogías son tan numerosas y precisas que nos llevan a creer que esta lámina en particular, u otra muy parecida, ${ }^{6}$ fue el modelo de Guaman Poma. Las semejanzas entre las huacas y los príncipes/niños no son directas, pero las que existen entre el santo y el Inca no dan lugar a dudas (Fig. 20, 21).

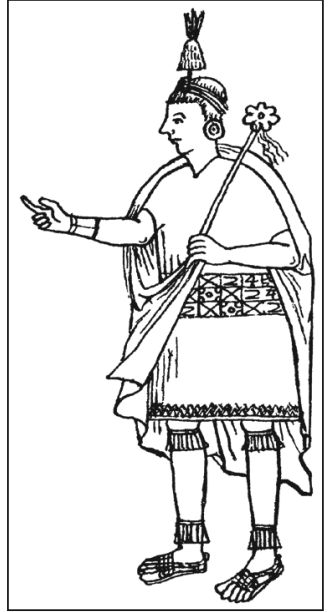

Figura 20

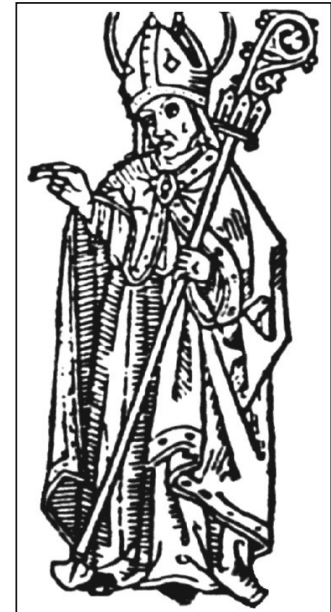

Figura 21

Sacamos las mismas conclusiones en lo que se refiere al martirio de Ramón Llull y el castigo de los indios adúlteras: las similitudes entre las víctimas son menores, pero entre los verdugos, son indiscutibles (Fig. 22, 23). ${ }^{7}$

6 Una misma representación podía tener múltiples variantes ya que, a causa del precio muy elevado de los grabados, los impresores se los intercambiaban, alquilaban o los hacían copiar por artistas. Eso explica también por qué una imagen podía aparecer varias veces en una misma edición.

7 El recurso a la imaginería hagiográfica no debe sorprender. Guaman Poma la conocía muy bien y puede haberse inspirado en ella para, al menos, unos diez dibujos (Prévôtel [en preparación, mayo de 2015]). 


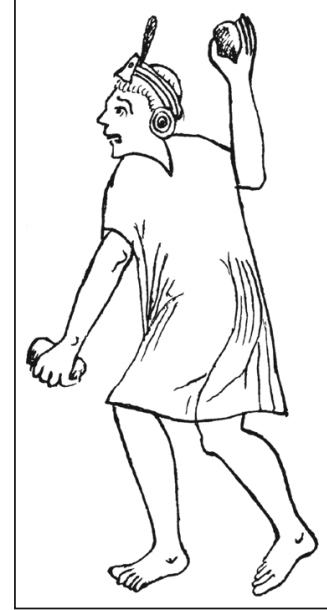

Figura 22

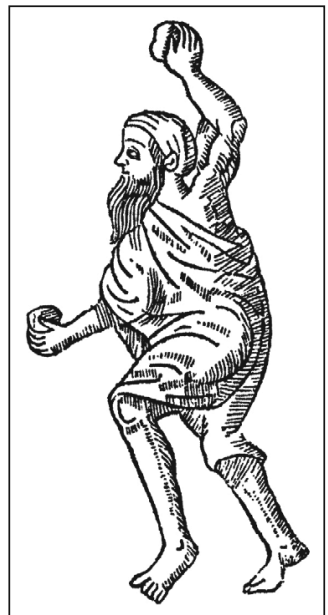

Figura 23

En el examen comparativo previo, hemos comentado varias veces el uso del rayado, elemento característico de los grabados que sirve, por ejemplo, para representar los pliegues de la ropa, las asperidades del suelo, la profundidad, las sombras o dar una impresión de volumen. El recurso constante a esa técnica permite comprender que Guaman Poma anhelaba imitar las estampas que podía ver en los libros impresos. En absoluto preveía pintar los dibujos de su propio manuscrito, quizá por motivos materiales como el precio elevado de los pigmentos. Pero como lo señaló Thomas Cummins, la cantidad de papel que necesitó para su crónica "indica que Guaman Poma tuvo acceso a suministros europeos como pocos de sus contemporáneos" (Cummins 2002: 207); además las acuarelas que realizó para Murúa prueban que tuvo acceso a pigmentos y "conocía la técnica de color" (ibid.: 208). Entonces, el dibujante imitó intencionalmente el grabado para "transcender la apariencia artesanal de un manuscrito. Al hacerlo así, quería dar a la Nueva corónica i buen gobierno el status de una obra impresa que le otorgara la autoridad e importancia que la reproducción mecánica daba a un libro impreso en el siglo XVII" (ibid.: 209). Como su autoría y el contenido de su obra no le conferían la legitimidad necesaria para la publicación de su libro, intentó compensarla mediante una conformidad formal.

El dibujo de Mama Huaco (Fig. 7), y más precisamente el motivo del espejo, requiere varias observaciones. Al examinar esta imagen, Rolena Adorno notó cierta falta de realismo: dada la posición del espejo, éste no podía reflejar la 
AudREy PrÉVOTEL

cara de la Coya. Entonces interpretó este detalle como un deseo, por parte del dibujante, de incluir al lector en el espacio de la escena (Adorno 1979: 3336). Para Michel Graulich y Serge Núñez Tolin, tal interpretación era abusiva. Ellos afirmaron que este reflejo no era más que una manera de representar el espejo y, citando un ejemplo publicado, ${ }^{8}$ que era muy común en aquel entonces (Graulich y Núñez Tolin 2000: 71). Efectivamente, lo confirman los cuatro grabados que hemos relacionado con el retrato de Mama Huaco (Fig. 8, $9,10,11)$.

Pero el aspecto que más nos interesa en el caso de Mama Huaco, es el valor simbólico del espejo. Van de Guchte recordó que generalmente era el atributo de las alegorías de la lujuria y de la vanidad. Reprodujo una imagen alemana con la característica del espejo/reflejo y señaló también similitudes con el grabado de una virgen que ilustra un libro hagiográfico. Concluyó pues que, para Guaman Poma, la figura de Mama Huaco era muy compleja ya que era a la vez una reina y una prostituta, un símbolo de vanidad y una virgen (van de Guchte 1992: 106-107). De hecho, el cronista dice de la Coya que era muy linda -"fue muy hermocícima muger" (Guaman Poma 1989: 121)- pero también que era responsable de la introducción de la idolatría entre los indios -"esta dicha señora fue primer enbentadora las dichas uacas ýdolos y hecheserías, encantamientos, y con ello les engañó a los dichos yndios" (ibid.: 81)- y que era una mujer de mala vida -"esta dicha muger dizen que fue gran fingedora (tachado: puta), ydúlatra, hichesera"; "dizen que se echaua con los hombres que ella quería de todo el pueblo" (loc. cit.). Desde luego, acorde al texto y la imagen, el dibujante parece haber acudido al espejo y el peine para simbolizar la belleza y la lujuria, haciendo de Mama Huaco una reina hechicera de mala vida. Corresponde con su teoría según la cual los indios, descendientes de Adán y Eva, no siempre fueron idólatras.

Sin embargo, gracias al examen detallado de las palabras utilizadas por Guaman Poma para hablar de Mama Huaco, tanto en español como en idiomas indígenas, Jan Szemiński ${ }^{9}$ (1997) propuso otra interpretación de esta figura. El análisis de los términos mama y waqu, en quechua y en aymara, le permiten subrayar la importancia del significado "que alimenta", así como su frecuente asociación con la tierra. Además, estudió los equivalentes quechuas de la supuesta lista de insultos en español -"esta dicha muger dizen que fue gran fingedora (tachado: puta), ydúlatra, hichesera, el qual hablaua con los

8 Maarten van de Guchte reprodujo un naipe alemán que representa la reina de las flores, una linda señora que tiene, en la mano derecha, un espejito redondo que refleja su cara aunque está frente al lector (van de Guchte 1992: 106).

9 Le agradecemos por habernos llamado la atención acerca de la figura de Mama Huaco en la Nueva Corónica. 
demonios"- y se dio cuenta de que esos términos también tenían que ver con la función alimentadora y la veneración. Su conclusión es la siguiente:

Las palabras con las cuales Guaman Pomas describió a Mama Waqu pueden ser una serie de insultos; sin embargo creo que no lo son y describen a una divinidad, una versión local de la Pacha Mama, la cual había instituído un culto y obligado a las wakas a responder a sus fieles. (Szemiński: 135) ${ }^{10}$

Entonces, ¿cómo se podrían conciliar las dos interpretaciones que tenemos del personaje de Mama Huaco? Pensamos que la contradicción se resuelve cuando tomamos en cuenta el doble lenguaje de la Nueva Corónica, motivado por la existencia de un doble destinatario. Es decir que, para un lector europeo y/o que no conoce los idiomas indígenas, tanto el texto -"fingedora (tachado: puta), ydúlatra, hichesera"- como el dibujo -espejo y peine- hacen de Mama Huaco una mujer seductora y propensa a la lujuria. Sin embargo, quizá un lector indígena pueda reconocer en este mismo personaje la señora o la diosa alimentadora revelada por Jan Szemiński. Creemos que Guaman Poma superpuso los códigos para que el lector europeo viera en Mama Huaco una mujer de mala vida, pero que el lector andino reconociera una divinidad. La ambivalencia del símbolo del espejo apoya esta hipótesis. Como lo notó van de Guchte, el espejo se podía asociar con la lujuria, pero también con la virginidad y el carácter sagrado de la Virgen, lo que sabía Guaman Poma como lo muestra su otra representación de la mujer con el espejo: en el Galvin Murúa, es una virgen del sol (Fig. 24).

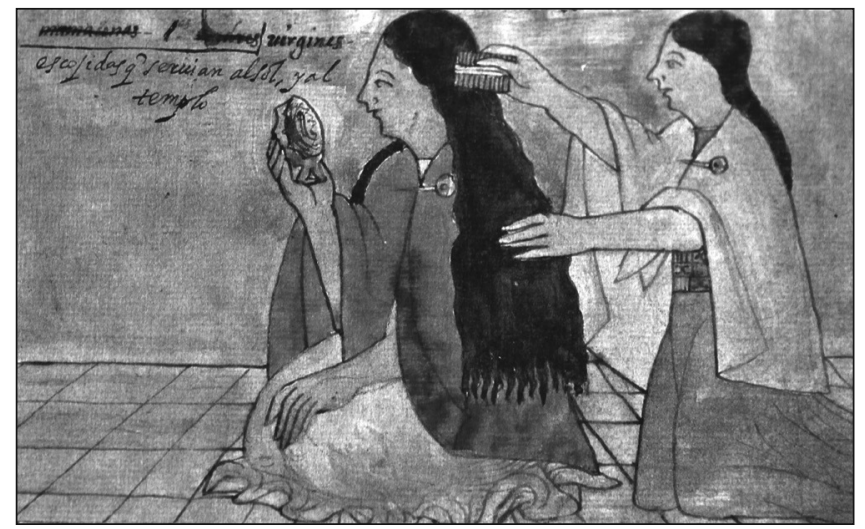

Figura 24

10 El análisis linguístico completo se encuentra en el capítulo "Manqu Qhapaq, sin padre conocido" (Szemiński 1997: 127-141). 
AudRey PréVOTEL

Por fin, la asociación entre Mama Huaco y la Virgen también es posible si consideramos que ambas tuvieron un hijo con un padre invisible y de carácter divino: Dios o el dios Sol. De modo que para Mama Huaco, el espejo no simbolizaría la virginidad sino más bien la divinidad y las afinidades con la virgen de los cristianos.

En lo referente a las similitudes entre varios dibujos de la Nueva Corónica (Fig. 1, 3, 4, 5) y distintas alegorías de la Iconologia de Cesare Ripa, son particularmente llamativas las que conciernen el Cielo (Fig. 2) y los Incas Manco Capac (Fig. 1), Sinchi Roca (Fig. 3) y Huayna Capac (Fig. 4); pero tampoco son suficientes como para autorizarnos a afirmar con certeza que la Iconologia sirvió de modelo a Guaman Poma. Y de todos modos, si consultó el libro de Ripa y encontró en él algunos modelos, es evidente que no se trata de la edición de 1624-25 -puesto que la crónica se terminó en 1615. Pero puede ser la de 1603 o la de 1613 por ejemplo, ya que ambas fueron ricamente ilustradas.

Por fin, en lo tocante a las parejas y las cenas, es casi cierto que los grabados de los Cromberger reproducidos aquí no fueron los modelos de Guaman Poma. Como en el caso anterior, lo único posible es suponer que el dibujante se inspiró en grabados análogos. No obstante, a pesar de que no son fuentes directas, permiten sacar una conclusión: las imágenes laicas formaron parte de los modelos utilizados por el dibujante. Clive Griffin indica que las cenas y parejas ilustraban ediciones de las fábulas de Esopo y precisa que la gran popularidad de dichas fábulas condujo varios artistas a realizar copias de los grabados utilizados por los Cromberger (Griffin 1988: 195-6). A lo mejor los modelos de Guaman Poma sean unas de esas copias. La única certeza que tenemos es que las imágenes laicas no carecen de interés en el marco de la búsqueda de las fuentes visuales de Guaman Poma.

\section{Conclusión}

El análisis comparativo pone en evidencia numerosas analogías entre dibujos de la Nueva Corónica y grabados europeos, lo que permite comprender que Guaman Poma aspiraba a que sus dibujos tuvieran la apariencia de láminas y que muchos de sus modelos pictóricos se encontraban en libros impresos. Gracias a la calidad y la cantidad de ciertas semejanzas, logramos identificar dos fuentes directas que pertenecen al ámbito religioso. A pesar de que las correspondencias con los otros grabados son menores, permiten proponer otras dos fuentes posibles -la Iconologia de Ripa y las fábulas de Esopo-, pero sobre todo demostrar que Guaman Poma tenía acceso a libros laicos y que acudió a un repertorio de imágenes muy amplio para elaborar sus propios dibujos. Por fin, el análisis del motivo del espejo hace posible otra interpretación de la figura de Mama Huaco: la imagen de la hechicera depravada se dirigiría al 
lector europeo, pero no borraría el carácter sagrado de este personaje para el lector andino. Aquí trasparece el doble discurso de la Nueva Corónica.

\section{Referencias bibliográficas}

ADORNO, Rolena (1979): "Of caciques, coyas and kings: the intricacies of points of view" en Dispositio, IV (10), pp. 27-47.

ADORNO, Rolena, BOSERUP, Ivan (2008). “The Making of Murúa’s Historia General del Piru”. En: Thomas Cummins y Barbara Anderson (eds) The Getty Murúa: Essays on the Making of Martin de Murúa's 'Historia General del Piru,' J. Paul Getty Museum Ms. Ludwig XIII 16. Los Angeles: Getty Research Institute.

CABOS FONTANA, Marie-Claude (2000). Mémoire et acculturation dans les Andes : Guaman Poma de Ayala et les influences européennes (1583-1615). París: L'Harmattan.

CUMMINS, Tom, OSSIO, Juan (2013). “Muchas veces dude real Mag. Açeptar esta dicha ympressa': la tarea de hacer La famossa historia de los reyes incas de Fray Martín de Murúa”. En: Juan Carlos Garavaglia, Jacques Poloni-Simard, Gilles Rivière (dir.) Au miroir de l'anthropologie historique. Mélanges offerts à Nathan Wachtel. Rennes : Presses Universitaires de Rennes, pp. 151-170.

CUMMINS, Thomas (2002): "Los Quilcakamayoq y los dibujos de Guaman Poma”. En Carmen Arellano Hoffman, Peer Schmidt, Xavier Noguez (coord.) Libros y escritura de tradición indígena: ensayos sobre los códices prehispánicos y coloniales de México. Zinacantepec, Eischstätt: Estado de México, El Colegio Mexiquense / Universidad Católica de Eischstätt, pp. [185]-215.

GISBERT, Teresa (1992). “The artistic world of Felipe Guaman Poma de Ayala”. En: Rolena Adorno, Mercedes López-Baralt, Tom Cummins, John V. Murra, Teresa Gisbert, Maarten van de Guchte, Guaman Poma de Ayala: the colonial art of an Andean author. New York: Americas society, pp. 75-91.

GISBERT, Teresa (1980). Iconografía y mitos indígenas en el arte. La Paz: Libreros Editores.

GRAULICH, Michel, NÚÑ̃EZ TOLíN, Serge (2000): "Les contenus subliminaux de l'image chez Felipe Guaman Poma de Ayala” en Journal de la société des Américanistes, 86, pp. [67]-112.

GRIFFIN, Clive (1988). The Crombergers of Seville: the history of a printing and merchant dynasty. Oxford: Clarendon Press.

GUAMAN POMA DE AYALA, Felipe (2008, 1aㅡ ed. 1993) [1615]. Nueva corónica y buen gobierno. Franklin Pease G.Y. (ed.), vocabulario y textos andinos por Jan Szemiński. Lima: Fondo de Cultura Económica.

GUAMAN POMA DE AYALA, Felipe (1989, 1aa ed. 1936) [1615]. Nueva corónica y buen gobierno. Paul Rivet (ed), introducción de Richard Pietschmann. París: Institut d'ethnologie.

GUCHTE (van de), Maarten (1992). "Invention and assimilation: European engravings as models for the drawings of Felipe Guaman Poma de Ayala”. En: Rolena Adorno, Mercedes López-Baralt, Tom Cummins, John V. Murra, Teresa Gisbert, Maarten van de Guchte, Guaman Poma de Ayala: the colonial art of an Andean author. New York: Americas society, pp. 92-109. 
HOLLAND, Augusta E. (2008). Nueva Corónica: tradiciones artísticas europeas en el virreynato del Perú. Cuzco: Centro de Estudios Regionales Andinos Bartolomé de Las Casas.

LÓPEZ-BARALT, Mercedes (1988). Icono y conquista: Guaman Poma de Ayala. Madrid: Hiperión.

LYELL, James P. R. (2006, 1aa ed. 1926). La ilustración del libro antiguo en España, Julián Martín Abad (ed). Madrid: Ollero y Ramos Editores.

MENDIZÁBAL LOSACK, Emilio (1961): "Don Phelipe Guaman Poma de Ayala, Señor y príncipe último quellqacamayoc" en Revista del Museo Nacional, 301, pp. 228-330.

MICHAUD, Cécile (2009). “Introducción”. En: Cécile Michaud, José Torres Della Pina (eds) De Ámberes al Cusco. El grabado europeo como fuente del arte virreinal. Lima: Impulso Empresa de Servicios SAC, pp. 11-12.

OJEDA, Almerindo (2009). "El grabado como fuente del arte colonial: estado de la cuestión”. En: Cécile Michaud, José Torres Della Pina (eds) De Ámberes al Cusco. El grabado europeo como fuente del arte virreinal. Lima: Impulso Empresa de Servicios SAC, pp. 15-21.

PEÑA, Beatriz Carolina (2011). Imágenes contra el olvido. El Perú colonial en las ilustraciones de fray Diego de Ocaña. Lima: Fondo Editorial de la Pontificia Universidad Católica del Perú.

PRÉVÔTEL, Audrey (en preparación, 2015). "A central aspect of the intellectual, religious and artistic context of the Nueva Corónica: lives of the saints". En: Rolena Adorno e Ivan Boserup (eds) Unlocking the Doors to the Worlds of Guaman Poma and his Nueva corónica. Copenhague: Museum Tusculanum Press.

RÉAU, Louis (1956). Iconographie de l'art chrétien. París: Presses Universitaires de France.

RIPA, Cesare (1624-25). Della novissima Iconologia di Cesare Ripa Pervgino. Padua: Pietro Paolo Tozzi (Biblioteca Nacional de España).

SZEMIŃSKI, Jan (1997). De las vidas de Inka Manqu Qhapaq. Cáceres: Fundación Xavier de Salas.

VEGA, Pedro de la (1580). Flos sanctorum. Sevilla : Fernando Díaz.

VORAGINE, Jacques de (2004) [siglo XIII]. La légende dorée. Alain Boureau y Monique Goullet (dir). París: Gallimard.

From the printed book till the Nueva corónica. The engravings as a source of Guaman Poma 